\title{
Culture of Spontaneously Contracting Myocardial Cells from
} Adult Rats

\author{
Stuart L. Jacobson \\ Department of Biology, Carleton University, Ottawa, Ontario, KIS 5B6, Canada
}

\begin{abstract}
A method is described for isolating single myocardial cells from adult rats and for establishing them in culture. Isolation is achieved by simultaneous enzymatic and mechanical treatment of excised cardiac tissue. Exposure to the enzymes, a mixture of trypsin and collagenase, is carried out in a specially designed apparatus in which enzyme-loosened cells are liberated from the tissue. Cells are spontaneously contractile upon isolation, establish in culture, and continue to contract for up to 60 days. Features of the isolation procedure are discussed and are compared with those of conventional procedures. Preliminary results are reported showing that isolated cells are sensitive to electric stimulation and to application of L-epinephrine.
\end{abstract}

Cultured myocardial cells isolated from avian or mammalian species by enzymatic treatment provide a valuable preparation for investigation of cardiac function. Procedures of choice for preparation of cultures, e. g., Kasten (15), employ modifications of methods pioneered by Cavanaugh (2) and Harary and Farley (7) and derive cells from cardiac tissue of embryonic or neo-natal animals. Various methods have been used to isolate single myocardial cells from adult tissue but attempts to prepare cultures of spontaneously contractile cells from animals older than about 14 days have failed $(1,8,15,16,33,34)$.

Long-term cultures of myocardial cells derived from adult animals could offer opportunities for biochemical, pharamacological, and physiological investigation not available with cultures from immature animals. How and why cells of adult-derived cultures differ from those from immature animals is one obvious area for study. In addition it might become possible to conduct experiments in vitro on cells which have been influenced in situ by disease or other phenomena manifest only in mature animals (cf. 31).

A method is described here for preparing long term cultures of spontaneously contractile myocardial cells isolated from mammals at various stages of postnatal development including adulthood. The purpose of this report is to give details of the preparative procedure and to establish, by reporting preliminary results, the validity and utility of the method. Papers to follow will report details of development of the cultures and results of other experiments.

\section{MATERIALS AND METHODS}

Tissue disaggregation apparatus. Cells are isolated by simultaneous enzymatic and mechanical treatment of excised myocardial tissue. Trypsin and collagenase are used in a specially 


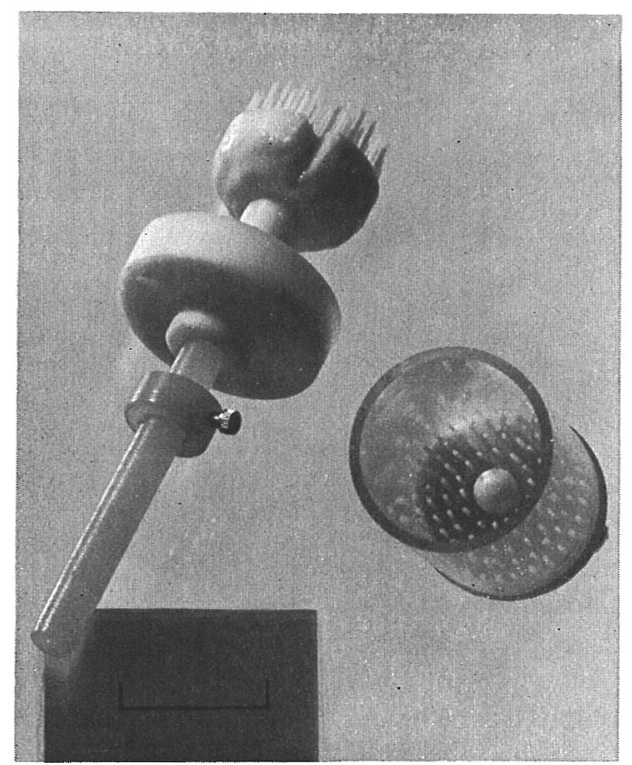

Fig. 1. The device (finger apparatus) used in mechanical treatment of heart tissue. Scale bar is $2 \mathrm{~cm}$ long. Detailed description in text.

fabricated apparatus which removes enzyme-loosened cells by a gentle abrading action of silicone elastomer fingers. Fig. 1 shows the device (finger apparatus) used in the isolation procedure.* Two disks with four circular rows of round finger-like projections are cast from Dow-Corning type 382 Medical Grade Elastomer (Dow Corning Corp., Medical Products Division, Midland Michigan, U.S.A.). One (lower) disk is held stationary being glued (Silastic Medical Adhesive, Silicone Type A, Dow Corning Corp., Medical Products Division, Midland Michigan, U.S.A.) fingers-up into one end of a $25 \mathrm{~mm}$ diameter glass tube with which it forms a liquid-tight vessel. The other (upper) disk mounted on a nylon shaft is rotatable and fits freely, fingers down, into the vessel. The nylon shaft passes through a teflon piece which serves as a bearing and as a tightly fitting cap for the vessel. The rows of fingers on the upper and lower disks interdigitate when the apparatus is assembled, and the lower disk has a central hub-like projection which fits into a complementary fingerless area of the upper disk. The hub prevents tissue from accumulating in the central region where the finger speed is lowest. The upper disk and teflon cover respectively have a segmental slot and a hole which when aligned permit insertion of a teflon tube for injection or withdrawal of solution. A nylon collar clamped to the shaft with a set screw allows the degree of interdigitation of fingers to be set. The shaft of the apparatus is flexibly coupled to a reduction gear train driven by a variable speed motor.

Preparative procedure. A Wistar or Sprague Dawley rat is decapitated and the thoracic cavity is opened to expose the heart. Using aseptic technique, about one-third to one-half of the apical end of the heart is cut off with a scissors. The excised tissue is transferred to a flat glass plate submerged in a dish of Saline A (22) at $21^{\circ} \mathrm{C}$. The tissue is minced into $2-4 \mathrm{~mm}$ fragments by vertical chopping strokes of an unsterilized but freshly unwrapped double edge razor blade. Minced tissue is rinsed briefly in a second dish of Saline A and placed in the apparatus. Four milliliters of enzymatic medium are added to the vessel. The medium consists of

* A detailed drawing is available from the author. Inquiries about the availability of fabricated apparatuses may be directed to A.A. Raffler, Science Workshop, Carleton University, Ottawa, K1S 5B6, Canada. 
0.05 percent collagenase (Sigma Chemical Co., no. C0130) and 0.25 percent trypsin (Sigma Chemical Co., no. T1005) in Saline A. The finger apparatus is placed in a $35^{\circ} \mathrm{C}$ water bath and the upper disk is rotated at from 4 to $12 \mathrm{rpm}$.

Liberated cells are harvested every 30 minutes. In harvesting, the enzymatic medium with isolated cells in suspension is slowly withdrawn into a syringe and the apparatus is refilled with $4 \mathrm{ml}$ of fresh medium. The cell suspension is centrifuged at $80 \mathrm{~g}$ for 10 minutes at $21^{\circ} \mathrm{C}$. The centrifuged enzymatic medium is decanted and sedimented cells are resuspended in $4 \mathrm{ml}$ of growth medium. Growth medium is 80 percent medium 199 (Grand Island Biological Co., no. E-12) and 20 percent fetal calf serum (Grand Island Biological Co., no. 614). Equal volumes of resuspension are plated into two $35 \mathrm{~mm}$ diameter plastic petri dishes (Falcon Co., no. 1008) containing $22 \mathrm{~mm}$ square glass coverslips. The coverslips are pretreated by soaking about 30 minutes in 3 percent $\mathrm{HCl}$ solution followed by a distilled water rinse and subsequent soaking for 20 minutes in 0.1 percent $\mathrm{Na}_{2} \mathrm{CO}_{3}$ followed by profuse rinsing in distilled water and drying in an oven at $38^{\circ} \mathrm{C}$. Treated coverslips are sterilized by exposure to (dry) $200^{\circ} \mathrm{C}$ heat overnight.

Cultures are maintained in a $35^{\circ} \mathrm{C}$ incubator with a $95 \%$ air $-5 \% \mathrm{CO}_{2}$ atmosphere at 90 percent relative humidity. Each 10-14 days 50-75 percent of the growth medium in a culture is aseptically removed and replaced with fresh medium. Solutions used in the preparative procedure are made up with deionized double-distilled water and are sterilized by two passages through $0.2 \mu \mathrm{m}$ pore size membrane filters (Sartorius Co., type no. 11107). Solutions are buffered by $0.175 \mathrm{~g} \mathrm{NaHCO}_{3}$ and $0.490 \mathrm{~g}$ of HEPES (Sigma Chemical Co., no. H3375) per liter and $\mathrm{pH}$ is finally adjusted to $7.4 \pm 0.1$ by addition of 0.3 molar $\mathrm{NaOH}$ or $\mathrm{HCl}$. Osmolarity of solutions is checked by measurement of freezing point depression and must be $300 \pm 10$ mOsm to be acceptable. With the exception of decapitation of the rat and of centrifugation, the entire procedure is carried out aseptically in a laminar flow hood equipped with a HEPA filter. To avoid possible side-effects antibiotics are not used. Cultures are observed in phase contrast on an inverted microscope equipped with a $35^{\circ} \mathrm{C}$ stage incubator supplied with a continuous flow of humidified gas mixture of $5 \% \mathrm{CO}_{2}$ and $95 \%$ air.

\section{RESULTS}

Cell viability and yield. With very rare exceptions the method described here produces isolated myocardial cells exhibiting spontaneous contractility and morphological integrity in culture for a minimum of 24 hours. An estimated 20 percent of the cultures contain myocardial cells which continue to contract spontaneously for only 24 to 48 hours. These cultures show extensive fibroblastic growth but the myocardial cells degenerate and contractile loci fail to develop. About 60 percent of the cultures develop loci which continue to contract spontaneously for 7 to 14 days and about 20 percent develop loci which continue to contract spontaneously for 14 to 30 days. On a few occasions cultures developed loci which continued to contract spontaneously for 60 days at which time they were fixed for histological examination. No attempts have been made to maintain cultures with spontaneously contractile loci for more than 60 days. Cell viability determined by dye exclusion was measured for 11 preparations from donors 28 to 105 days old. Newly harvested cells were plated in Saline A plus trypan blue as described by Phillips (26) and assayed for ability to exclude dye. Viability ranged from 50 to 97 percent. Two preparations had viabilities of less than 80 percent and eight had viabilities greater than 90 percent.

Cell yields were obtained by counting aliquots of culture innocula. Both a hemocytometer and a specially designed chamber of $0.1 \mathrm{ml}$ volume were used in the counting procedure. The 30 minute harvest contains cellular debris and blood cells and occa- 
sionally some myocardial cells. Successive harvests have markedly fewer blood cells, and about the same amount of debris and an increasing number of spontaneously contractile myocardial cells. The 90 or 120 minute harvests usually produce the greatest yield. The yield of cells ranges widely even under apparently identical conditions. However, the following generalizations can be made. Yield is inversely related to the age of the animal (donor) from which cells are derived. For a rat younger than 30 days the yield is of the order $10^{3}$ to $10^{4}$ cells per $\mathrm{ml}$ of medium. For a rat between 30 and 300 days the yield is of an order 10 to 100 times lower. Occasionally a multicellular clump is harvested along with the isolated cells but this is a rare occurrence.

Newly harvested cells can be classified into two morphologically distinct groups, round or elongated. Round cells can be further classified as striated and optically dense, or as optically transparent. All of the elongated cells are striated. Over 90 percent of the elongated cells from donors over 60 days old are binucleate with the remaining ones being mono or tri-nucleate. In neo-natal animals a somewhat smaller percentage of elongated cells are binucleate and the large majority of round cells are mononucleate.

Development in culture. Elongated myocardial cells from donors 1 to 300 days old initially undergo a characteristic morphological change, becoming round and optically dense. Both the rate at which this transition takes place and the number of cells which remain viable throughout are inversely related to the age of the donor. Cells from neo-natal donors have not yet been studied extensively but they have been observed to undergo the transition in from 1 to 12 hours. Judging these cultures by the relative lack of degenerated cells after the transition, the high percentage of cells attached to the substratum, and the relatively rapid subsequent development, viability is very high. In the case of cells from older donors (e.g., 120 days old) the transition takes 12 to 72 hours and only about 20 percent of the cells attach to the substratum and show subsequent development. The other approximately 80 percent of cells in these cultures initially develop an irregular (rough) outline and a disorganized granular cytoplasm and finally fall into total disarray.

Development subsequent to completion of the elongate to round transition depends upon the age of the donor. For donors up to about 30 days old, growth and division appear to proceed rapidly. Usually in about 4 to 7 days a contiguous layer of fibroblastic cells develops and numerous contractile myocardial cell loci are in evidence. Such loci frequently exhibit synchronous contractility extending over a few cell diameters. For donors over about 60 days old, development is slower. In 6 to 10 days a contiguous layer of primarily fibroblastic cells develops. Within this layer are located isolated and apparently unicellular contractile loci. After 10 to 20 days in culture these loci spread and flatten out into a characteristic shape with two nuclei in evidence. Fig. 2 is a sequence of photomicrographs showing, in phase contrast, the development of a spontaneously contractile locus in a culture from a 120 day rat.

Spontaneous contractility. It is not unusual to observe that contractile cells from donors of all ages undergo periods of quiescence lasting from a few minutes to a few days. It is therefore necessary to repeatedly observe a locus in order to decide whether it is capable of spontaneous contractility.

Elongated cells show two kinds of contractile activity. The most common, type one, is a longitudinal shortening with an amplitude of 25 to 30 percent of the restlength of the cell. The second kind of contractility, type two, does not result in any 


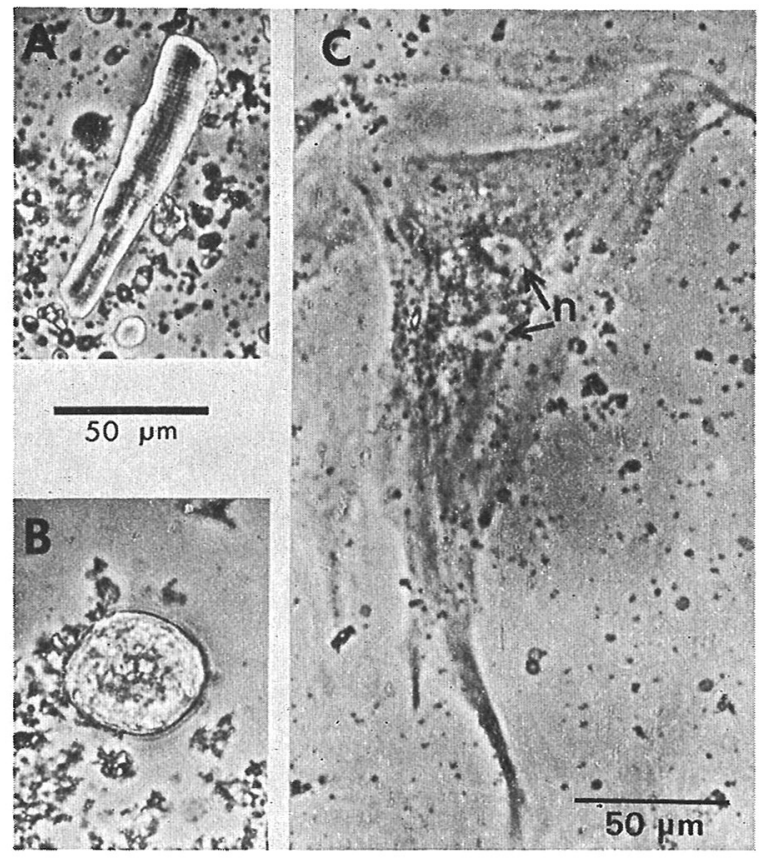

Fig. 2. Phase contrast photomicrographs of three of the stages in development of spontaneously contractile loci derived from isolated adult rat myocardial cells. A, Elongated cell shortly after plating. $\mathrm{B}$, Cell 3 days in culture after completion of elongate to round transition. $\mathrm{C}$, Well developed binucleate locus after 13 days in culture. $n$, nucleus. Cells were contracting spontaneously when photographed. Granular material in background is cell debris.

appreciable shortening of the cell. Instead it is manifest as a wave-like propagation of a narrow, optically distinct, transverse region of the cell. The wave-regions arise spontaneously at various points along the cell and can propagate in either longitudinal direction. A similar phenomenon termed "escalation" has been described for cultured skeletal muscle of chick embryos (6). Contractility of established loci is unlike either type one or two. Here contraction is a forceful tremulous motion in a region of cytoplasm within the locus.

Contractile frequency of cells in a single culture or of the same cell at different times can vary over a wide range. Frequencies from 0.02 to $5 \mathrm{~Hz}$ have been observed. Higher rates may occur but are virtually impossible to measure without a special detector. A contractile frequency of 3 to $5 \mathrm{~Hz}$ is often precursive to sudden cell deterioration.

Electrical and pharmacological sensitivity. A preliminary study indicates that isolated cells are sensitive to electrical stimulation and to application of L-epinephrine. Cells prepared from 35 to 112 day old rats were tested 2 days after being placed in culture. Electrical stimulation was accomplished by passing $0.1 \mathrm{msec}$ current pulses of $10^{-7}$ to $10^{-5} \mathrm{~A}$ between two $\mathrm{Ag}-\mathrm{AgCl}$ electrodes. The electrodes contacted Saline A salt bridges immersed in the culture medium. The stimulating (negative) salt bridge was a glass micropipette of about $1.5 \mu \mathrm{m}$ tip diameter and the positive salt bridge was a glass tube plugged with a Saline A-soaked cotton wick. The cell being stimulated was positioned between the salt bridges 1 to $3 \mu \mathrm{m}$ from the micropipette. Eleven of 18 
quiescent elongated cells and 12 of 13 spontaneously contractile elongated cells contracted in response to stimulation. In the case of round optically dense cells, 4 of 17 quiescent and 2 of 5 spontaneously contractile cells contracted in response to stimulation.

Cells were tested for sensitivity to L-epinephrine by application of 3 to $10 \mu \mathrm{l}$ of a solution of $4.5 \times 10^{-7} \mathrm{M}$ concentration in Saline A with 2 percent $(\mathrm{v} / \mathrm{v})$ trypan blue viability test solution added (cf. reference 22). Application of the drug was accomplished by ejection of solution from a micropipette of about $30 \mu \mathrm{m}$ tip diameter located 1-3 $\mu \mathrm{m}$ from the cell. Visual monitoring of the ejected drug was facilitated by the added dye. Application of the solution without L-epinephrine added was tried on 11 cells as a control. Eight of the control cells were spontaneously contractile and three were quiescent. No change was observed in any of the control cells with respect to contractile rate, threshold stimulus current, or contractile amplitude when the control solution was applied. The drug solution was applied to seven elongated cells, three of which were spontaneously contractile and four quiescent. The three contractile cells showed a transient $(10-60 \mathrm{sec})$ response with increased contractile frequency and/or amplitude. For the quiescent cells, drug application lowered the threshold current for initiation of contraction and in one case increased the amplitude of contraction elicited by a constant stimulus.

\section{DISCUSSION}

The method described here provides a new preparation for investigation of myocardial function. It would be satisfying, if not useful, to understand the basis for its success. Unfortunately, like many cell culture techniques, mystery is one pervasive ingredient and is likely to be displaced only by a costly program of experiments. Notwithstanding this, some insights might be obtained from considering a few major differences between the present method and more conventional methods.

Relative mildness of mechanical treatment and high purity of enzymes to which the tissue is subjected are two outstanding features of the present method. Cells subjected to washing, centrifugation, or repeated pipetting are known to be adversely affected, perhaps through the loss of membrane or cytoplasmic components $(17,21,28)$. A magnetic stirbar or pipetting are commonly employed in disaggregation of cardiac tissue. These treatments are generally followed by filtration and/or centrifugation for harvesting cells which have been released from tissue. Few workers report the angular velocity of stirbar or centrifuge used in their cell isolations. However the maximum $12 \mathrm{rpm}$ of the finger apparatus is considerably slower than the slowest speed attainable by ordinary commercially made magnetic stirrers. Furthermore, harvesting cells by centrifugation at $80 \mathrm{~g}$ is a very gentle treatment relative to that used in the few cases where such data are reported. On the basis of these facts it is reasonable to infer that the mechanical treatment of the present method is more gentle than that normally used.

Various enzymes have been used to isolate myocardial cells $(9,15,28,30,33)$. Some workers have suggested the use of enzymes other than trypsin and some note that highly purified enzymes may be advantageous. However most still employ relatively crude preparations of trypsin. In early stages of development of the present method crude enzyme preparations were tried. These were abandoned however when 
use of more highly purified preparations increased the yield of intact cells and reduced the number of damaged cells. This was not entirely unexpected since it is known that trypsin does enter cardiac cells during isolation and does do some intracellular damage $(13,14)$. In the case of cells from adult donors, impurities in enzyme preparations might destroy cells outright or might cause latent injury predisposing cells to mechanical damage.

As the embryonic heart develops, intercellular junctions are relatively simple in structure and limited in number. The complexity and number of junctions increases postpartum until juvenile life $(3,23)$. Perhaps this is the basis of the relative difficulty of obtaining robust myocardial cells from adult donors. Cell injury associated with cleavage of numerous intercellular junctions could render cells more fragile and thereby make gentle mechanical treatment a very critical factor in promoting subsequent in vitro survival. It is clear that cells isolated by the present method (from donors of all ages) exhibit an elongated, striated morphology very similar to that in situ $(24,34)$. This and the fact that the cells can contract spontaneously and continually from the time of isolation is in sharp contrast to neo-natal and embryonic myocardial cells isolated by conventional methods. It is taken as an indicator of the relatively low degree of damage done by the present method. Conventionally isolated cells are round and do not show spontaneous contractility until about 16 to 24 hours in culture. The onset of contractility corresponds to the time at which they become attached to the culture substratum. It has been suggested (7) that the initial delay of contractility is related to a requirement of the contractile process for development of tension. Abundant evidence that cardiac contractility and myocardial tension or deformation are intimately related is reviewed by Jensen (10). It is possible that a cytoskeletal structure which initially allows isolated cells to maintain their elongated shape in vitro also supplies a resistive structure for development of intracellular tension facilitating spontaneous contractility.

The amount of debris harvested is a major drawback of the method. It might be possible to alleviate this problem by secondary treatment, such as gradient centrifugation. However it is likely that additional treatment will decrease the already low in vitro survival. The abundance of debris at harvest and the subsequent failure of many myocardial cells from adult donors to develop into beating loci are indicative of cell damage and seem inconsistent with the high viability measured by dye exclusion. A similar result was found with myocardial cells isolated from chick embryos (18). In this case dye exclusion measurements indicated a 68 percent viability but only 40 percent of cells survived in vitro. It seems likely that viability as determined by dye exclusion is a necessary but not sufficient condition for in vitro survival. Such viability measurements apparently fail to detect certain types of damage which finally reduce in vitro survival.

A limited investigation was carried out to determine the effect on cell yield and amount of debris when some parameters of the procedure were varied. Enzyme concentration and mixture, interharvest interval, speed of centrifugation, speed of finger apparatus and dimensions of the elastomeric fingers were varied systematically. A control and an experimental finger apparatus were used in every trial. Each apparatus contained one-half of the cardiac tissue excised from the donor animal. In general, effects on yield and debris due to to changes in parameters were small relative to the apparently inherent variability of the method. For example, a change of enzyme con- 
centration of two-fold in either direction was required to produce an obvious and consistent effect. Further investigations of this type might result in second order improvements of the method but for the present it seems safe to assume that these parameters are nearly optimal.

One of the interesting and potentially utilitarian characteristics of myocardial cells derived from adult donors is the apparent absence of cell division in vitro, accompanied by extensive cell growth. Lack of cell division in vitro is consistent with the behaviour of myocardial cells in situ. During early development of rats (5) and mice (25) the heart increases in size initially due to both cell division and cell growth. After a critical age cell growth accounts for further size increase and cell division stops. The critical ages are 48 and 112 days for rats and mice, respectively. It is evident (Fig. 2C) that after 2 to 3 weeks in culture, spontaneously contractile loci which develop from adult-derived cells are of very large size.

Efforts have been made $(4,11,12,19,27,29,32)$ to find or to develop an ideal vertebrate myocardial preparation for voltage clamp studies. A single contractile cell (fiber) of about $50 \mu \mathrm{m}$ wide and upwards of $200 \mu \mathrm{m}$ long would be likely to approximate the ideal size. One approach to this problem is an attempt to produce giant myocardial fibers by guiding cell growth in vitro. To date, one of the more promising efforts to obtain cells with the requisite size and proclivity for growth is induction of coalesence of embryonic myocardial cells (20). Preliminary results apparently are encouraging but details have not yet been reported. Large initial size and demonstrated ability for extensive growth suggest that myocardial cells from adult donors could be ideal starting material for production of giant fibers. Investigation of this possibility is now in progress.

Acknowledgment. Charlotte Schultz deserves highest praise for her constant devotion to the arduous task of preparing and observing cultures during the entire course of this work. Bruce Kennedy performed the experiments which demonstrate cells' sensitivity to electrical stimulation and epinephrine. Teresa Schwarzfeld prepared and photographed the cells in Fig. 2. The skill and ingenuity of Cliff Wilson in fabrication of special apparatus is gratefully acknowledged. This research was supported by a grant from the National Research Council of Canada (to S.L. Jacobson).

\section{REFERENCES}

1. BLоом, S. Requirements for spontaneous contractility in isolated adult mammalian heart muscle cells. Exp. Cell Res. 69, 17-24, 1971

2. Cavanaugh, M. Pulsation migration and division of dissociated chick embryo heart cells in vitro. J. Exp. Zool. 128, 573-585, 1955

3. Challice, C. and S. Viragh. The embryologic development of the mammalian heart. In Ultrastructure of Biological Systems, Vol. 6, The Mammalian Heart, ed. Challice, C. and S. Viragh, Academic Press, New York, p. 103, 1973

4. DeHaAn, R. and H. Fozzard. Membrane response to current pulses in spheroidal aggregates of embryonic heart cells. J. Gen. Physiol. 65, 207-222, 1975

5. EnsCo, M. and C. Le Blond. Increase in cell number as a factor in the growth of organs and tissues of the young male rat. J. Embryol. Exp. Morphol. 10, 530-562, 1962

6. Griffin, J., A. Coleman, J. Coleman, K. Chapman and J. Weltman. Escalation: a newly observed phenomenon in cultured embryonic muscle cells. Biophysical Society Abstracts Sixteenth Annual Meeting. Biophys. J. 12, 76a, 1972

7. Harary, I. and B. Farley. In vitro studies of single isolated beating heart cells. Science 131, 1674-1675, 1960 
8. Harary, I. and B. Farley. In vitro studies on single beating rat heart cells. 1. Growth and Organization. Exp. Cell Res. 29, 451-465, 1963

9. Hilfer, R. Collagenase treatment of chick heart and thyroid. In Tissue Culture Methods and Applications, ed. Kruse, P.F. and Patterson, M.K., Jr., Academic Press, New York, p. 14, 1973

10. Jensen, D. Intrinsic Cardiac Rate Regulation. Appleton-Century-Crofts, New York, 1971

11. Johnson, E. and J. Sommer. A strand of cardiac muscle; its ultrastructure and the electrophysiological implications of its geometry. J. Cell Biol. 33, 103-129, 1967

12. Johnson, E. and M. Lieberman. Heart: excitation and contraction. Ann. Rev. Physiol. 33, $479-532,1971$

13. KASTEN, F. Electron microscope studies of the combined effects of trypsinization and centrifugation on rat heart cells with observations of early cultures. J. Cell Biol. 31, 131A, 1966

14. Kasten, F. Cytology and cytochemistry of mammalian myocardial cells in culture. Acta Histochem. 9, 775-808, 1971

15. Kasten, F. Mammalian myocardial cells. In Tissue Culture Methods and Applications, ed. Kruse, P.F. and Patterson, M.K., Jr., Academic Press, New York, p. 72, 1973

16. Kono, T. Roles of collagenases and other proteolytic enzymes in the dispersal of animal tissues. Biochem. Biophys. Acta 178, 397-400, 1968

17. Levine, S. Effect of manipulation on ${ }^{32} \mathrm{P}$ loss from tissue culture cells. Exp. Cell Res. 19, 220227,1960

18. Levinson, C. and J. Green. Cellular injury resulting from tissue disaggregation. Exp. Cell Res. 39, 309-317, 1965

19. Lieberman, M., T. Swanobori, J. Kootsey and E. Johnson. A synthetic strand of cardiac muscle: Its passive electrical properties. J. Gen. Physiol. 65, 527-550, 1975

20. Lieberman, M., T. Swanobori, N. Shigeto and E. Johnson. Physiologic implications of heart muscle in tissue culture. In Developmental and Physiological Correlates of Cardiac Muscle, ed. Lieberman, M. and Sano, T., Raven Press, New York, p. 139, 1975

21. Lowry, O., J. Carter, J. WARD and L. Glaser. The effect of carbon and nitrogen sources on the level of metabolic intermediates in E. coli. J. Biol. Chem. 246, 6511-6521, 1971

22. Marcus, P., T. Cieciura and J. Puck. Clonal growth in vitro of epithelial cells from normal human tissues. Exp. Med. 104, 615-628, 1956

23. Muir, A. An electron microscope study of the embryology of the intercalated disc in the heart of the rabbit. J. Biophys. Biochem. Cytol. 3, 193-202, 1957

24. Muir, A. Further observations on the cellular structure of cardiac muscle. J. Anat. Lond. 99, $27-46,1965$

25. Petersen, R. and R. Baserga. Nucleic acid and protein synthesis in cardiac muscle of growing and adult mice. Exp. Cell Res. 40, 340-352, 1965

26. Phillips, H. Dye exclusion tests for cell viability. In Tissue Culture Methods and Applications, ed. Kruse, P.R. and Patterson, M.K., Jr., Academic Press, New York, p. 406, 1973

27. Purdy, J., M. Lieberman, A. Roggeveen and G. Kirk. Synthetic strands of cardiac muscle: Formation and ultrastructure. J. Cell Biol. 55, 563-578, 1972

28. RinALDini, L. An improved method for the isolation and quantitative cultivation of embryonic cells. Exp. Cell Res. 16, 405-477, 1959

29. SACHS, F. Electrophysiological properties of tissue cultured heart cells grown in linear array. J. Memb. Biol. 28, 373-399, 1976

30. Smith, T. and W. Berndt. The establishment of beating myocardial cells in long term culture in fluid medium. Exp. Cell Res. 36, 179-191, 1964

31. Sobel, H. Effect of age on cardiac metabolism. In Recent Advances in Studies on Cardiac Structure and Metabolism, 1, ed. Bajusz, E. and RonA, G., University Park Press, Baltimore, Md., p. 101,1972

32. Sommer, J. and E. Johnson. Cardiac muscle: a comparative study of Purkinje fibers and ventricular fibers. J. Cell Biol. 36, 497-526, 1968

33. Vahouney, G., R. Wei, R. Starkweather and C. Davis. Preparation of beating heart cells from adult rats. Science 167, 1616-1618, 1970

34. Yokoyama, H., R. Jennings and W. Wartman. Intercalated disks of dog myocardium. Exp. Cell Res. 23, 29-44, 1961 